\title{
Death Reflection and Employee Work Behavior in the COVID-19 New Normal Time: The Role of Duty Orientation and Work Orientation
}

\author{
Shilong Wei ${ }^{1}$, Yuting He ${ }^{1}\left(\mathbb{D}\right.$, Wenxia Zhou ${ }^{1, *}$, József Popp ${ }^{2,3}{ }^{\mathbb{D}}$ and Judit Oláh ${ }^{3,4}$ (D) \\ 1 School of Labor and Human Resources, Renmin University of China, Beijing 100872, China; \\ shilongwei@ruc.edu.cn (S.W.); 2019102684@ruc.edu.cn (Y.H.) \\ 2 John von Neumann University, National Bank of Hungary, Research Center, 6000 Kecskemét, Hungary; \\ poppjozsef55@gmail.com \\ 3 College of Business and Economics, University of Johannesburg, Johannesburg 2006, South Africa; \\ olah.judit@econ.unideb.hu \\ 4 Faculty of Economics and Business, University of Debrecen, 4032 Debrecen, Hungary \\ * Correspondence: zhouwx@ruc.edu.cn
}

check for updates

Citation: Wei, S.; He, Y.; Zhou, W.;

Popp, J.; Oláh, J. Death Reflection and Employee Work Behavior in the COVID-19 New Normal Time: The Role of Duty Orientation and Work Orientation. Sustainability 2021, 13, 11174. https://doi.org/10.3390/ su132011174

\section{Academic Editors:}

Dan-Cristian Dabija, Catalina

Soriana Sitnikov, Anca Bandoi,

Dana Danciulescu and

Cristinel Vasiliu

Received: 13 September 2021

Accepted: 7 October 2021

Published: 10 October 2021

Publisher's Note: MDPI stays neutral with regard to jurisdictional claims in published maps and institutional affiliations.

Copyright: (C) 2021 by the authors. Licensee MDPI, Basel, Switzerland. This article is an open access article distributed under the terms and conditions of the Creative Commons Attribution (CC BY) license (https:/ / creativecommons.org/licenses/by/ $4.0 /)$.

\begin{abstract}
Coronavirus disease 2019 (COVID-19) is a destructive affair for both workplace and community. However, with the strengthen of global anti-pandemic measures, COVID-19 becomes the norm and there is an increased trend for people to reflect on life or death. Moreover, regardless of its facilitating role in advancing organizational behavior (OB) study, very few studies empirically examine the effects of death reflection in the work domain. Drawing on the generativity theory, we identify how death reflection influences employees' in-role and extra-role performance under the COVID-19 pandemic. A longitudinal study is performed by using multi-source data from 387 employees in China. Our results reveal that the COVID-19-triggered death reflection is associated with the stronger in-role performance and organizational citizenship behaviors. We find that duty orientation is the mechanism that can explain the effects of the COVID-19-triggered death reflection on employees' work behaviors. Furthermore, employees who reflect on death with high (vs. low) career and calling orientations tend to have higher in-role and extra-role performance, while employees who reflect on death with low (vs. high) job orientation are likely to have lower in-role and extra-role performance.
\end{abstract}

Keywords: death reflection; duty orientation; work orientation; job performance; COVID-19

\section{Introduction}

Employees are reminded of their impermanence by various affairs occurring inside and outside the organization [1]. For some employees, these reminders of mortality result in self-protection [2,3], leading to strong anxiety, huge stress, and absenteeism from work [4]. For others, they may trigger reflection about death and significance of life, facilitating more contributions to others and organizations [5]. Grant and Wade-Benzoni [1], Metcalfe and Mischel [6] both suggest that, after quickly experiencing the affect-driven "hot" reaction, known as death anxiety, Becker [7], a less emotionally "cool" cognitive system should start, known as death reflection that can be marked by thoughtful, analytical, and reasonable reactions according to systematic processing under intentional control [8].

There is no doubt that the Coronavirus disease 2019 (COVID-19) is an ongoing global health crisis. With the increasing numbers of infections and death, this illness has begun to influence the economy, organizations, and their employees. Tons of workers must work from home and experience isolation and anxiety [4,9]. However, though the tragedy of the COVID-19 pandemic has a significant detrimental effect on people's working life and behaviors, with the advent of the coronavirus vaccine, the COVID-19 pandemic seems to become the norm and people are learning how to coexist with COVID-19. At this moment, people have gone through changes in mind and cognition [9], for example, reduced level 
of death anxiety and increased level of death reflection [1]. Moreover, according to the typology of mortality cues introduced by Grant and Wade-Benzoni [1]'s research, the COVID-19 pandemic can be considered as a chronic external death-related event, which may trigger moderate or high level of death reflection.

Some social psychological researches have reported the distinctive and amazingly strong impacts of death reflection on individual's motivations and behaviors [10]. For instance, death reflection possibly motivates mature employees to pay more attention to the prosocial dimensions at work [11], participate in more positive leadership behaviors [12] and voluntary activities [13], or give up their work to seek more meaningful hobbies [14]. However, though repeated calling for in-depth research, Yuan, Baranik [15], not too much evidence can support to unfold the correlations between death reflection and employees' behaviors, in particular how and when these relationships happen [3]. Moreover, although some researches have examined the functional impact of death reflection on special occupations such as firefighters, OB research is still limited, especially in the domain of work spread to the general population [15].

To gain a better understanding of the underlying positive impacts of death reflection activated by the COVID-19 pandemic on employees' work behaviors, we developed an integrated model based on the generativity theory, which highlights the complicated process about how individuals respond to death in a positive mindset [16]. According to this theory, when individuals respond to death in a deliberate, analytical, and rational mode (death reflection), they will form two motives: the desire to make enduring contributions and the desire to contact others [13]. By strengthening these two prosocial motives to make meaningful dedication and contact, individuals may form a positive and dutiful mindset Yuan, Baranik [15] and perform higher levels of generative behaviors and, therefore, promoting the welfare of other people or groups [17]. Based on this, we proposed that within the domain of work, employees who have experienced death reflection are likely to form higher levels of duty orientation - an individual's volitional orientation to faithfully provide service and support for other group members, to strive for group tasks and missions, and to honor relevant norms and principles of the group [18]. In turn, such orientation may further influence employees' in-role and extra-role performance Eva, Newman [19], so that they may perform higher levels of in-role performance (IRP), which refers to regular in-role work behaviors that are undertaken to meet the job requirements, Williams and Anderson [20], as well as organizational citizenship behaviors (OCBs), which refers to discretionary extra-role work behaviors that are not part of the job description but promoting the efficient and effective functioning of the organization, aimed at individuals (OCBI) or the organization (OCBO) [21]. This part in our model examines why COVID19-triggered death reflection influences employees' in-role and extra-role performance (including IRP, OCBI, and OCBO).

The death reflection literature so far has theoretically posited that the manifestation of death reflection cannot be understood without its context [1]. Yet, very few empirical studies have examined the boundary condition of death reflection (Yuan et al., 2019). Moreover, Grant and Wade-Benzoni [1] proposed that employees may choose to express their motivations (e.g., the desire to make lasting contributions) or generative behaviors (e.g., make differences or help others) induced by death reflection outside the domain of work [22]. To respond to this, based on the resource allocation theories [23], work orientation (including job, career, and calling orientations), which captures the attachment values of employees to work, Wrzesniewski, Dutton [24], is introduced as the important individual contingency that may drive employees with death reflection to express generative behaviors inside or outside the workplace. In this regard, after experiencing death reflection, job-oriented employees who define their identities weakly in terms of work may choose to express their generativity outside the domain of work, while career-oriented or calling-oriented employees who invest their identities more strongly in work may have generative motivations or behaviors in the workplace [25]. Therefore, employees who reflect on death with high career or calling orientation may attempt to contribute to coworkers and organiza- 
tional prosperity through higher duty orientation and job performance as well as OCBs, while employees who reflect on death with high job orientation may have lower level of duty orientation and job performance and OCBs because they are unwilling to seek much meaning from work and invest less time or energy in the workplace [26]. This part of our model examines when COVID-19-triggered death reflection influences employees' job performance and OCBs.

The theoretical model is presented in Figure 1. We test the integrated model using a sample of 387 employees in China, where the indirect effects of COVID-19-triggered death reflection on employees' in-role performance and OCBs (via duty orientation) are moderated by work orientation. Although death reflection is linked to a variety of organizational variables including volitional unselfish behaviors [13], leadership behaviors [12], intrinsic goals [27], creativity [5], and career transition [21], the extent to which death reflection is associated with employees' performance remains unexplored. Thus, through this study, we clarify the effects of death reflection on employees' in-role performance and OCBs and enrich the growing literature on the effects of death reflection (or death awareness) on the workplace.

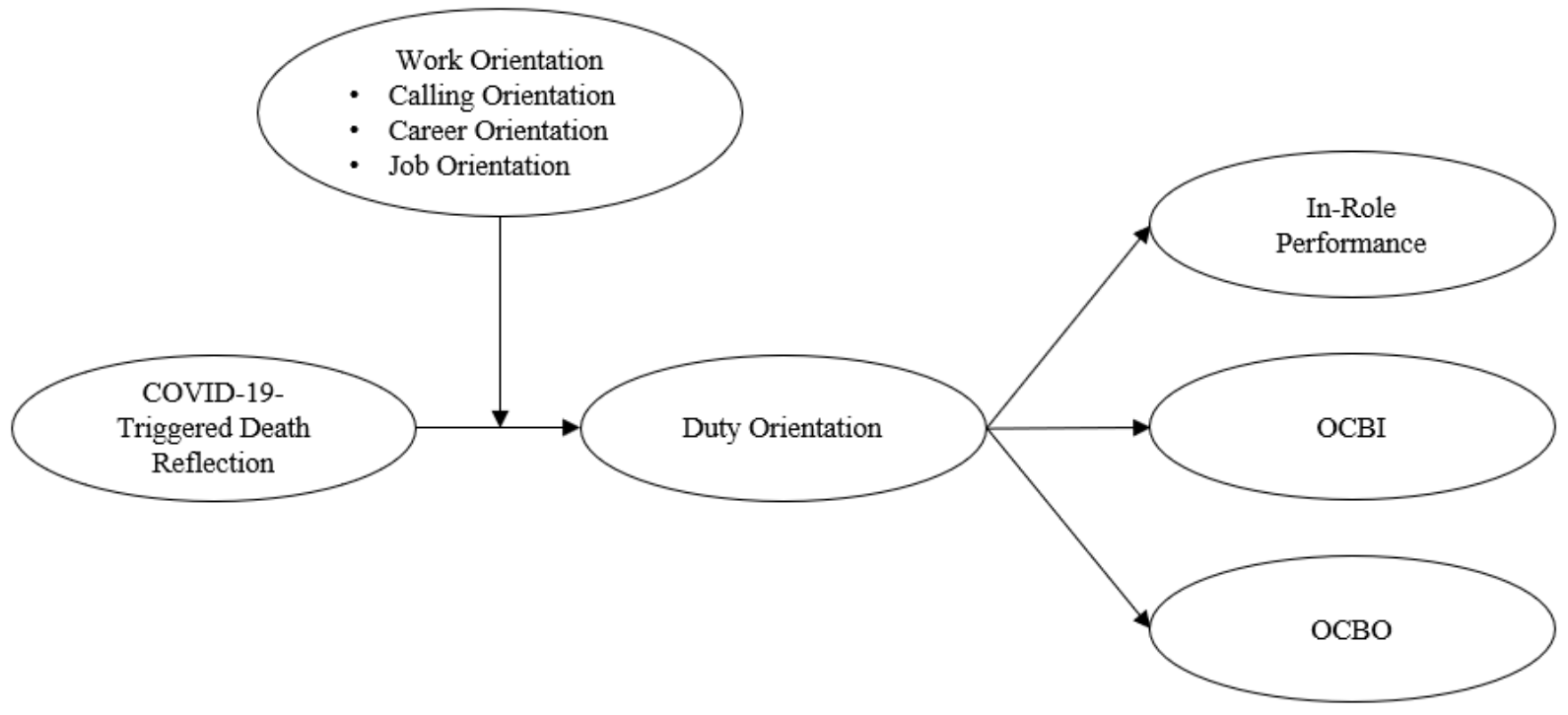

Figure 1. The proposed hypothesized model of our research. OCBI = Organizational Citizenship Behaviors toward Individuals. OCBO = Organizational Citizenship Behaviors toward Organization.

\section{Literature Review and Research Hypothesis}

\subsection{COVID-19-Triggered Death Reflection and Employees' Work Behaviors}

The coronavirus pandemic, a global long-term health disaster that caused millions of infections and deaths, can be considered as a chronic vicarious outside event that is more likely to trigger people's death reflection [1]. As we mentioned earlier, death reflection is the intentional processing of individuals for mortality, which focuses on the positive sides of death awareness [15]. According to the generativity research, the cool psychological processes of death reflection constitute the foundation for self-transcendent reactions portrayed by the generativity theory and relevant literature. Past near-death experiment research has demonstrated that individuals do not display self-protective reactions when being asked to engage in death reflection, and instead, when thinking about death in a reasonable and analytical manner, they perform prosocial and self-transcendent behaviors [28]. Based on the generativity theory, death reflection activated by mortality cues (e.g., the COVID-19 pandemic) may enhance prosocial motivation, and this is possibly associated with generative behaviors at a higher level, including help, guidance, motoring, or other efforts and initiative supporting others in tasks [1]. The commitment to becoming generative and self-transcendent displayed at work manifests the conscientiousness about individual or group performance. Under the work domain, we expect such positive 
generative behaviors are striving to accomplish tasks (in-role performance), helping other co-workers (OCBI), and enhancing social connections by promoting organizational welfare (OCBO). Therefore, the following hypothesis is proposed:

\section{Hypothesis 1: Death reflection is positively related to employees' (a) IRP, (b) OCBI, (c) OCBO.}

\subsection{Duty Orientation as a Mediator in the Relationship between COVID-19-Triggered Death Reflection and Employees' Work Behaviors}

Duty orientation consists of three key components of duty: a duty to provide loyal services and faithful support with group members (duty to members); a duty to finish organizational missions and tasks under sacrifice and extra efforts (duty to mission); and a duty to uphold the group principles and codes and insist on doing the right thing following group norms and morals [29]. Generally, the three elements of duty orientation contain the normative orientation to do the right thing for both the team and organization [29]. Employees with high duty orientation tend to take care of issues in the team or organization according to their duties to the team members and the organization. Therefore, they may be more willing to behave in a manner that facilitates the team and organization in comparison with those who have a low-level duty orientation [18].

We proposed that duty orientation is the instrument that links the COVID-19-triggered death reflection to employees' in-role and extra-role performance. This assertation stems from the theory of generativity McAdams and de St Aubin [16], which suggests that the selftranscendent generative behaviors triggered by death reflection result from two enhanced motives: the desire to offer long-term contributions and the desire to build up relationship with others [16]. Specifically, the desire to make lasting contributions refers to an agentic desire motivating individuals to make self-transcendent contributions and extend their contributions into the future, Wade-Benzoni [30], while the desire to feel connected with others refers to a communal desire, for it links individual behaviors and identify enduring relationships, groups, and organizations as well as institutions [31].

Through reinforcing such agentic and communal motives to meaningful contributions and contacts, employees who experience death reflection will generate a promotion-focused mindset to make contributions to others or groups [1]. With this in mind, within the domain of work, we expected that such mindset may be the employees' heightened volitional orientation towards the other members of the group and organization (duty orientation).

Furthermore, by performing the duty to team members, employees may engage in OCBs benefiting other team members (OCBI), as they are determined to provide loyal and faithful support for other team members. These behaviors involve altering their own work methods, providing help for those members in need. Duty orientation also reduces dysfunctional behaviors like bad-mouthing other team members [29].

In addition, through displaying duty to organizational mission, employees may perform their job duties to their maximum ability (in-role performance) and increase their OCBs towards the organization (OCBO), since duty to mission can reflect the degree to which employees have perceived their responsibility of supporting the organization through fully performing job duties and paying more efforts beyond their job role (Eva et al. 2020). Together, the following hypothesis is proposed:

Hypothesis 2: Duty orientation mediates the positive relationship between COVID-19-triggered death reflection and employees' (a) IRP, (b) OCBI, (c) OCBO.

\subsection{Work Orientation as a Moderator in the Mediated Relationship between COVID-19-Triggered Death Reflection and Employees' Work Behaviors through Duty Orientation}

As noted previously, in the workplace, death reflection is likely to trigger employees' duty orientation and link to higher levels of in-role performance and OCBs. However, generativity literature so far has emphasized that the manifestation of death reflection is shaped by individual differences so that employees are able to show their prosocial motivations or generative behaviors beyond the work domain [1]. From the perspectives 
of resource allocation theories [23], those employees who have reflected on death tend to realize that time is limited and thereby pay more attention on how to allocate their resources. Previous studies demonstrate that death reflection motivates individuals to decide the priority of tasks, goals, and activities according to their own values [27]. Based on this, we propose that employees' orientations toward work that provide a series of principles that determine their time and energy allocation, Wrzesniewski, Dutton [24], serves as the key individual contingency of how death reflection affects duty orientation and employees' work behaviors.

Employees generally have three work orientations, namely, job orientation, career orientation, and calling orientation [32]. For employees with job orientation, work is merely a means to achieve their values of supporting oneself, family, or leisure time. For employees with career orientation, work is a means to achieve values of one's status, promotions, achievement, and challenge. For employees with calling orientation, work is their personal goal, internal source of personal significance, and a means to achieve the value of helping others [26].

According to work orientation-related research, employees with job orientation do not strongly define personal identity by work [33]. Thus, it is expected that employees who reflect on death with high job orientations tend to express generative motivations or behaviors outside the domain of work, as they are unwilling to seek meaning from work [34]. Therefore, death reflection motivates employees with job orientation to engage in generative activities beyond the work domain, such as raising children or joining in voluntary activities, and devote less time and energy to their work. Therefore, we hypothesized:

Hypothesis 3a: Job orientation moderates the positive relationship between COVID-19-triggered death reflection and duty orientation such that this link is weaker on employees with a higher level of job orientation.

Hypothesis 3b: The indirect positive effects of COVID-19-triggered death reflection on employees' (a) IRP, (b) OCBI, (c) OCBO via increased duty orientation are moderated by job orientation such that the positive indirect effects are weaker on employees with a higher level of job satisfaction.

Furthermore, employees with high career orientation or calling orientation are more likely to express prosocial motivations or generative behaviors at work. These employees devote their identities more strongly in work compared with job-oriented employees [24]. Specifically, for job-oriented workers, work provides the core source of status and reputation [26]. Near-death experience studies reveal death reflection's role in broadening individual attentions from narrow career goals to wilder considerations about doing well [27]. These findings provide strong evidence that when experiencing death reflection, job-oriented workers may have a higher level of volitational orientation towards members, tasks, and codes of groups, and engage in more positive work behaviors so that they can achieve both agentic and communal goals of improving personal prestige and making contributions to others within the domain of work [1]. Therefore, we proposed:

Hypothesis 4a: Career orientation moderates the positive correlation of COVID-19-triggered death reflection and duty orientation, indicating that the stronger the link, the higher the level of career orientation.

Hypothesis 4b: The indirect positive effects of COVID-19-triggered death reflection on employees' (a) IRP, (b) OCBI, (c) OCBO via increased duty orientation are moderated by career orientation such that the positive indirect effects are stronger on employees with a high level of career orientation.

On the other hand, employees with calling orientation consider work as an underlying source of meaning, identity expression, as well as social contribution [35]. Therefore, we propose that high calling-oriented employees will express their prosocial motivations and engage in generative behaviors at work when they reflect on death. Moreover, when they notice opportunities of helping and mentoring others, they may craft their jobs and take 
initiative in providing more help or guidance, resulting in a higher level of organizational citizenship behaviors [36]. Moreover, they tend to show greater efforts and perseverance in tasks favoring other people (Grant, 2007). These arguments lead to the hypotheses:

Hypothesis 5a: Calling orientation moderates the positive correlation between COVID-19triggered death reflection and duty orientation such that the link is stronger on employees with a higher level of calling orientation.

Hypothesis 5b: The indirect positive effects of COVID-19-triggered death reflection on employees' (a) IRP, (b) OCBI, (c) OCBO via increased duty orientation are moderated by calling orientation such that the positive indirect effects are stronger on employees with a higher level of calling orientation.

\section{Research Methodology}

We collected data from a transportation company as well as an information technology (IT) company in Northern China during April to May 2021 with an online survey. (During this period, the COVID-19 pandemic in mainland China has been effectively controlled, the prevention of the COVID-19 pandemic, such as wearing masks and washing hands, more frequently becomes the norm). We chose these two companies for the following reasons: Firstly, employees from both companies worked normally during the COVID-19 pandemic crisis. Secondly, due to the need of work, employees from these two companies are able to get access to the information of the COVID-19 pandemic, including the infections and death, through the Internet, or anti-pandemic training. To reduce common method bias, we used a time-lagged design wherein we contacted the same participants three times with a one-week interval between each data collection point. At time 1, workers were asked to report COVID-19-triggered death reflection, job orientation, and their demographic variables of tenure, job position, age, gender, education. At time 2, workers were asked to report their duty orientation. At time 3, employees were asked to report their in-role and extra-role performance. Participants surveys were matched using their web IDs. We paid each participant 20 RMB (approximately 4 USD). From time 1 to time 3, we matched 387 samples. In our final sample, 247 were males and the other 140 were females, the average age was $29.3(\mathrm{SD}=4.7$, age ranges from 21 to 44 ), the average company tenure was 3.2 years $(S D=2.8)$, and $91.3 \%$ received college or above education. Participants came from various departments of both companies such as logistics, marketing, human resources, research and development.

\section{Measurement}

COVID-19-triggered death reflection. COVID-19-triggered death reflection was assessed with a revised version of Yuan, Baranik [15] 15-item Death Reflection Scale (DRS). Yuan, Baranik [15] presented evidence for the scale's reliability (Cronbach's alphas across four samples ranged from 0.86 to 0.93 , and the test-retest reliability coefficient was 0.60 over a one-year interval) and convergent, discriminant, and criterion validity. We created the COVID-19 version of the scale by adding COVID-19 related words. Average Cronbach's alpha in the present study was 0.89 .

To establish the validity and reliability of the revised version, we conducted a pretest in a sample of 266 employees of one IT company located in Northern China. The correlation between the COVID-19-DRS used in this study and the original DRS was 0.95. Adding the COVID-19 situation had little effect on the reliability of the scale (DRS $\alpha=0.94$; COVID-19DRS $\alpha=0.90$ ). Therefore, the COVID-19 version of the DRS appears to be comparable to the original DRS. Sample items include "when I think about death related to the COVID-19 pandemic, I feel like I should do more for the world", "when I think about death related to the COVID-19 pandemic, I feel a strong urge to help other people".

Duty orientation. Participants rated their duty orientation on the scale developed by Hannah et al. (2014). This scale consisted of 12 items of mission (4 items), codes ( 4 items), and members (4 items), which were rated with a 5-point Likert scale ranging from 1 (strongly disagree) to 5 (strongly agree). Sample items include "Put the interests of my team ahead of my personal interests", "Accept personal risk or loss in support of the 
mission/organization goals", "Do what is right always". In the current study, the average Cronbach's alpha coefficient was 0.92 .

Work orientation. We used an 18-item scale from Wrzesniewski, McCauley [26] that captures three dimensions of work orientation (job orientation, career orientation, and calling orientation). Sample items include: job orientation, "I am very conscious of what day of the work week it is and I greatly anticipate weekends"; Career orientation, "I view my job primarily as a stepping stone to other jobs"; Calling orientation, "I find my work rewarding"; Cronbach's alpha for each dimension was acceptable: job orientation $(\alpha=0.80)$, career orientation $(\alpha=0.83)$, and calling orientation $(\alpha=0.78)$.

Employee Work Behavior. Participants rated their work behaviors using the Williams and Anderson [20] 21-item scale, Eva, Newman [19], of which 7 items measure in-role performance, 7 items measure OCBI, and 7 items measure OCBO. Sample items include "Adequately completes assigned duties", "Help others who have heavy workloads", "Gives advance notice when unable to come to work". The Cronbach's alpha coefficient was 0.75, 0.87 , and 0.83 , respectively, and 0.84 in total.

Control Variables. We consider employee's tenure, job positions, and some demographic variables including gender, age, and education level as control variables. We chose these control variables based on [37]. Specifically, tenure can influence individual behaviors as employees with shorter tenure would work harder to build up new relationships [38]. Based on generativity theory, we include demographic variables such as age as a control variable because the generative behaviors emerge most prominently around midlife [16]. Furthermore, we controlled for employees' job positions primarily because if employees take on work that is high in helping opportunities, they are more likely to express generativity in their current jobs [39].

\section{Results}

Table 1 presents the descriptive statistics. We first performed a series of confirmatory factor analyses (CFA) using Mplus 8.3 to assess the distinctiveness of the measures completed in the survey. First, we estimated the hypothesized six-factor measurement model where all measures (i.e., COVID-19-triggered death reflection, duty orientation, work orientation, in-role performance, OCBI, OCBO) were distinct factors and were allowed to be correlated freely. The hypothesized measurement model displayed very good fit with the data, $\chi 2(319)=364.37, p<0.05$, comparative fit index $(\mathrm{CFI})=0.94$, Tucker-Lewis index $(\mathrm{TLI})=0.95$, root mean square error of approximation $($ RMSEA $)=0.06$, standardized root mean square residual $(S R M R)=0.04$. Then, we compared the hypothesized measurement model to three alternative models to test whether the measures of key constructs were distinct.

Table 1. Means, Standard Deviations, and Intercorrelations (Pearson) of the Measured Variables.

\begin{tabular}{|c|c|c|c|c|c|c|c|c|c|c|c|c|c|c|c|}
\hline Variable & 1 & 2 & 3 & 4 & 5 & 6 & 7 & 8 & 9 & 10 & 11 & 12 & 13 & $\mathbf{M}$ & SD \\
\hline 1. Gender & - & & & & & & & & & & & & & - & - \\
\hline 2. Tenure & $0.20^{* *}$ & - & & & & & & & & & & & & 3.23 & 2.81 \\
\hline $\begin{array}{l}\text { 3. Job } \\
\text { position }\end{array}$ & $0.12 *$ & 0.20 * & - & & & & & & & & & & & 3.17 & 0.96 \\
\hline 4. Age & -0.3 & $0.14^{*}$ & $0.19 * *$ & - & & & & & & & & & & 29.31 & 4.70 \\
\hline $\begin{array}{l}\text { 5. Education } \\
\text { level }\end{array}$ & 0.19 & 0.06 & $0.27^{* *}$ & 0.11 & - & & & & & & & & & 4.30 & 2.40 \\
\hline 6. CDR & $0.18^{* *}$ & $0.16^{*}$ & $0.32 * *$ & $0.22 * *$ & 0.08 & 0.89 & & & & & & & & 4.12 & 0.62 \\
\hline $\begin{array}{c}\text { 7. Job } \\
\text { orientation }\end{array}$ & $0.23 * *$ & $0.21 * *$ & $0.12 *$ & 0.04 & 0.07 & $0.14^{* *}$ & 0.80 & & & & & & & 4.21 & 0.92 \\
\hline $\begin{array}{l}\text { 8. Career } \\
\text { orientation }\end{array}$ & $0.11 *$ & $0.23 *$ & $0.10^{* *}$ & $0.15 *$ & 0.04 & $0.18^{*}$ & $-0.12^{* *}$ & 0.83 & & & & & & 4.30 & 0.83 \\
\hline $\begin{array}{l}\text { 9. Calling } \\
\text { orientation }\end{array}$ & $0.15^{* *}$ & $0.26^{* *}$ & $0.11 *$ & 0.06 & 0.06 & $0.21 *$ & $-0.10^{* *}$ & $0.17^{*}$ & 0.78 & & & & & 4.14 & 0.91 \\
\hline $\begin{array}{l}10 . \text { Duty } \\
\text { orientation }\end{array}$ & $0.14^{*}$ & 0.04 & $0.16^{* *}$ & 0.09 & 0.12 * & $0.39 * *$ & 0.13 & $0.32^{* *}$ & 0.24 ** & 0.92 & & & & 4.53 & 0.56 \\
\hline 11. IRP & $-0.13^{*}$ & $0.15^{*}$ & $0.11 *$ & $0.19^{* *}$ & 0.06 & $0.17^{*}$ & $0.13 *$ & $0.26 *$ & $0.19 * *$ & $0.39^{* *}$ & 0.75 & & & 3.67 & 0.79 \\
\hline 12. OCBI & -0.07 & 0.04 & $0.06 *$ & 0.11 & 0.10 * & $0.21^{* *}$ & 0.14 * & $0.20 * *$ & $0.18^{*}$ & $0.26^{* *}$ & $50 *$ & 0.87 & & 4.12 & 0.75 \\
\hline 13. ОСВО & -0.09 & $0.14 *$ & $0.13 *$ & $0.21^{* *}$ & 0.07 & $0.22 * *$ & $0.16^{*}$ & $0.23 * *$ & $0.20 *$ & $0.24^{*}$ & $0.52 *$ & 0.56 * & 0.83 & 3.87 & 0.75 \\
\hline
\end{tabular}

Note: $\mathrm{N}=387$. CDR = COVID-19-Triggered Death Reflection. IRP = In-Role Performance. OCBI = Organizational Citizenship Behaviors toward Individuals. OCBO = Organizational Citizenship Behaviors toward Organization. ${ }^{*} p<0.05 .{ }^{* *} p<0.01$. 
In the first alternative measure model, the correlation between duty orientation and OCBI was set to 1 . The result of chi-squared difference test indicated that the first alternative model fit the data significantly worse than the hypothesized measurement model where duty orientation and OCBI were distinct factors, $\chi 2(310)=657.29, p<0.01, \mathrm{CFI}=0.82$, $\mathrm{TLI}=0.89, \mathrm{RMSEA}=0.10, \mathrm{SRMR}=0.09$. In a second alternative measure model, we set the correlation between duty orientation and OCBO to 1 . This second alternative measurement model fit the data significantly worse than the hypothesized model where duty orientation and OCBO were distinct constructs, $\chi 2(310)=735.24, p<0.01, \mathrm{CFI}=0.80$, $\mathrm{TLI}=0.86, \mathrm{RMSEA}=0.12, \mathrm{SRMR}=0.11$. A five-factor model in which work orientation and duty orientation were collapsed onto one factor demonstrated a worse fit to the data, $\chi 2(310)=873.34, p<0.01, \mathrm{CFI}=0.71$, TLI $=0.70, \mathrm{RMSEA}=0.14, \mathrm{SRMR}=0.13$. In summary, the results from the confirmatory factor analyses support the discriminant validity of the measures.

We proposed that COVID-19-triggered death reflection is related to higher job performance including IRP, OCBI, and OCBO (Hypothesis 1). The bivariate correlations between COVID-19-triggered death reflection and IRP $(\mathrm{r}=0.17, p<0.05)$, OCBI $(\mathrm{r}=0.21, p<0.01)$, and OCBO $(\mathrm{r}=0.22, p<0.01)$ respectively provided preliminary support for Hypotheses 1 (see Table 1). As shown in Model 1-3 of Table 2, results indicated that, COVID-triggered death reflection was positively related to IRP $(b=0.15, p<0.05$; Model 1 , Table 2$)$. The results also indicated that COVID-triggered death reflection was positively related to OCBI $(b=0.18, p<0.01$; Model 2, Table 2) and OCBO ( $b=0.20, p<0.01$; Model 3, Table 2), respectively. Hypothesis 1, thus, received support.

Table 2. Summary of Hierarchical Regression Results.

\begin{tabular}{|c|c|c|c|c|c|c|}
\hline & IRP & OCBI & OCBO & & uty Orientatic & \\
\hline Predictor & Model 1 & Model 2 & Model 3 & Model 4 & Model 5 & Model 6 \\
\hline Gender & $-0.08(0.07)$ & $-0.06(0.04)$ & $0.06(0.04)$ & $0.05(0.03)$ & $0.04(0.03)$ & $-0.02(0.03)$ \\
\hline Tenure & $0.04 *(0.02)$ & $-0.08(0.04)$ & $-0.07(0.06)$ & $-0.07(0.05)$ & $-0.04(0.05)$ & $-0.05(0.05)$ \\
\hline Job position & $0.07 *(0.03)$ & $0.05 *(0.04)$ & $0.08 *(0.05)$ & $0.06(0.04)$ & $0.04(0.03)$ & $0.07(0.03)$ \\
\hline Age & $0.09(0.07)$ & $0.07(0.03)$ & $0.06(0.04)$ & $0.06(0.02)$ & $0.07(0.02)$ & $0.06 *(0.02)$ \\
\hline Education & $0.03(0.02)$ & $-0.07(0.03)$ & $-0.04(0.03)$ & $0.03(0.02)$ & $0.04(0.02)$ & $-0.02(0.02)$ \\
\hline CDR & $0.15 *(0.04)$ & $0.18 * *(0.07)$ & $0.19 * *(0.06)$ & $0.16 *(0.07)$ & $0.13 *(0.05)$ & $0.14 *(0.06)$ \\
\hline Job orientation & & & & $-0.11(0.09)$ & & \\
\hline $\mathrm{CDR} \times$ Job orientation & & & & $0.13 *(0.12)$ & & \\
\hline Career orientation & & & & & $0.30 * *(0.14)$ & \\
\hline $\mathrm{CDR} \times$ Career orientation & & & & & $0.42 * *(0.25)$ & \\
\hline Calling orientation & & & & & & $0.25^{* *}(0.13)$ \\
\hline $\mathrm{CDR} \times$ Calling orientation & & & & & & $0.38 * *(0.23)$ \\
\hline Duty orientation & $0.52 * *(0.07)$ & $0.43 * *(0.04)$ & $0.35^{* *}(0.05)$ & & & \\
\hline $\mathrm{R}^{2}$ & 0.10 & 0.12 & 0.14 & 0.09 & 0.28 & 0.17 \\
\hline Adjusted $\mathrm{R}^{2}$ & 0.04 & 0.06 & 0.08 & 0.04 & 0.22 & 0.14 \\
\hline
\end{tabular}

Note: $\mathrm{N}=387$. CDR = COVID-19-Triggered Death Reflection. IRP = In-Role Performance. OCBI = Organizational Citizenship Behaviors toward Individuals. OCBO = Organizational Citizenship Behaviors toward Organization. Bootstrap sample. Coefficients are standardized. Standard errors are shown in parenthesis. ${ }^{*} p<0.05$. ${ }^{* *} p<0.01$.

We proposed that duty orientation mediates the relationship between COVID-19triggered death reflection and job performance (IRP, OCBI, OCBO) (Hypothesis 2). We assessed mediation based on $95 \%$ bias-corrected confidence intervals (CIs) constructed through 5000 bootstrapped samples (Hayes, 2013). Specifically, for in-role performance, the indirect effect of COVID-19-triggered death reflection (via duty orientation) on IRP (indirect effect $=0.10,95 \%$ CI $[0.032,0.126]$ ) was statistically significant. For OCBs, the indirect effect of COVID-19-triggered death reflection (via duty orientation) on OCBI (indirect effect $=0.15,95 \%$ CI $[0.047,0.203]$ ) and on OCBO (indirect effect $=0.13,95 \% \mathrm{CI}$ $[0.056,0.218])$. These results provide support for Hypothesis 2. Furthermore, data also shows that all mediating effects are partial.

We proposed that three types of work orientation moderate the effect of COVID19-triggered death reflection on duty orientation (Hypothesis 3a, 4a, 5a). Specifically, in Hypothesis $3 a$, we proposed that job orientation moderates the effect COVID-19-triggerd 
death reflection on duty orientation such that compared to high job orientation employees, those with low job orientation will generate greater duty orientation. The interaction term of COVID-19-triggered death reflection and job orientation was statistically significant for duty orientation ( $b=-0.13, p<0.05$; Model 4 , Table 2).

In Hypothesis $4 \mathrm{a}$, we proposed that career orientation moderates the effect COVID-19triggerd death reflection on duty orientation such that compared to low career orientation employees, those with high career orientation will generate greater duty orientation. The interaction term of COVID-19-triggered death reflection and career orientation was statistically significant for duty orientation ( $b=0.42, p<0.01$; Model 5 , Table 2$)$.

In Hypothesis $5 \mathrm{a}$, we proposed that calling orientation moderates the effect COVID-19triggerd death reflection on duty orientation such that compared to low calling orientation employees, those with high calling orientation will generate greater duty orientation. The interaction term of COVID-19-triggered death reflection and calling orientation was statistically significant for duty orientation $(b=0.38, p<0.01$; Model 6 , Table 2$)$.

For job orientation, results indicated that there was a stronger positive relationship between COVID-19-triggered death reflection and duty orientation when job orientation was low than when job orientation was high (see Figure 2a). For career orientation, results indicated that there was a stronger positive relationship between COVID-19-triggered death reflection and duty orientation when career orientation was high than when career orientation was low (see Figure 2b). Results show the positive correlation between COVID19-triggered death reflection and duty orientation when calling orientation was high than when calling orientation was low (see Figure 2c).

Furthermore, in Hypotheses $3 b, 4 b$, and $5 b$, we proposed that the indirect effects of COVID-19-triggered death reflection on job performance (IPR, OCBI, OCBO) via duty orientation are stronger when career orientation and calling orientation are high or job orientation is low than when career orientation and calling orientation are low or job orientation is high.

For job orientation, the conditional indirect effect of COVID-19-triggered death reflection on IRP via duty orientation was significant when job orientation was low $(-1 S D$, indirect effect $=-0.07,95 \% \mathrm{CI}=[-0.193,-0.132])$ compared with when job orientation was high $(+1 S D$, indirect effect $=-0.01,95 \% C I=[-0.121,0.013])$ (see Table 3$)$. The conditional indirect effect of COVID-19-triggered death reflection on OCBI via duty orientation was significant when job orientation was low $(-1 S D$, indirect effect $=-0.12$, $95 \% \mathrm{CI}=[-0.232,-0.053])$ compared with when job orientation was high $(+1 S D$, indirect effect $=-0.09,95 \% \mathrm{CI}=[-0.027,0.009]$ ) (see Table 3). The conditional indirect effect of COVID-19-triggered death reflection on OCBO via duty orientation was significant when job orientation was low $(-1 S D$, indirect effect $=-0.13,95 \% \mathrm{CI}=[-0.143$, $-0.098]$ ) compared with when job orientation was high $(+1 S D$, indirect effect $=-0.06$, $95 \% \mathrm{CI}=[-0.381,0.142])($ see Table 3$)$.

Table 3. Estimates and Bias-Corrected Bootstrapped 95\% Confidence Intervals for the Conditional Effect of COVID-19-Triggerd Death Reflection on Job Performance (via Duty Orientation) at $\pm 1 S D$ of Job Orientation.

\begin{tabular}{cccc}
\hline Outcome Variable & Level of Job Orientation & Indirect Effect & Confidence Interval \\
\hline IRP & $-1 S D$ & -0.07 & {$[-0.193,-0.132]$} \\
& $+1 S D$ & -0.01 & {$[-0.121,0.013]$} \\
OCBI & $-1 S D$ & -0.12 & {$[-0.232,-0.053]$} \\
& $+1 S D$ & -0.09 & {$[-0.027,0.009]$} \\
OCBO & $-1 S D$ & -0.13 & {$[-0.143,-0.098]$} \\
& $+1 S D$ & -0.06 & {$[-0.381,0.142]$} \\
\hline
\end{tabular}

Note: $\mathrm{N}=387$. IRP = In-Role Performance. OCBI = Organizational Citizenship Behaviors toward Individuals $\mathrm{OCBO}=$ Organizational Citizenship Behaviors toward Organization. Bootstrap sample size $=5000$. 
(a)

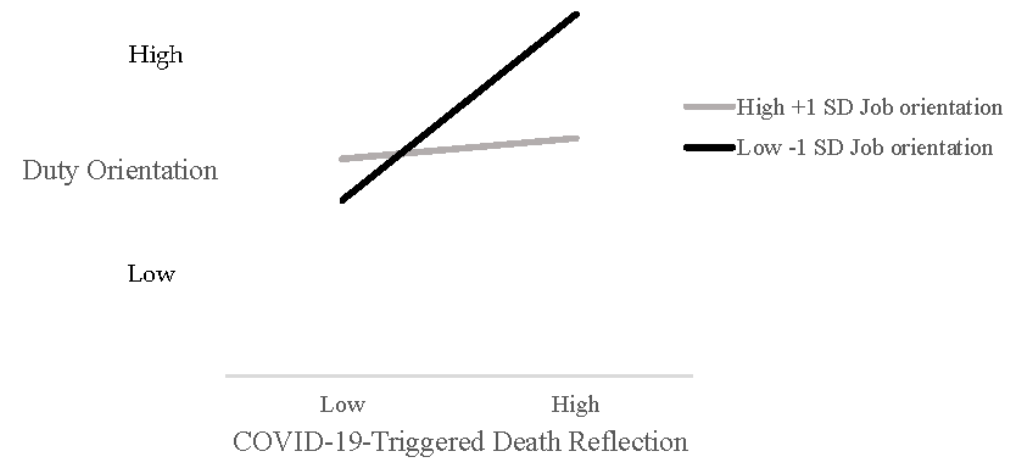

(b)

High

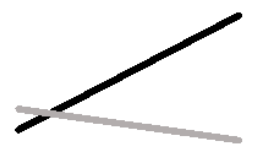

- High +1 SD Career orientation

Duty Orientation

Low -1 SD Career orientation

Low

Low

High

COVID-19-Triggered Death Reflection

(c)

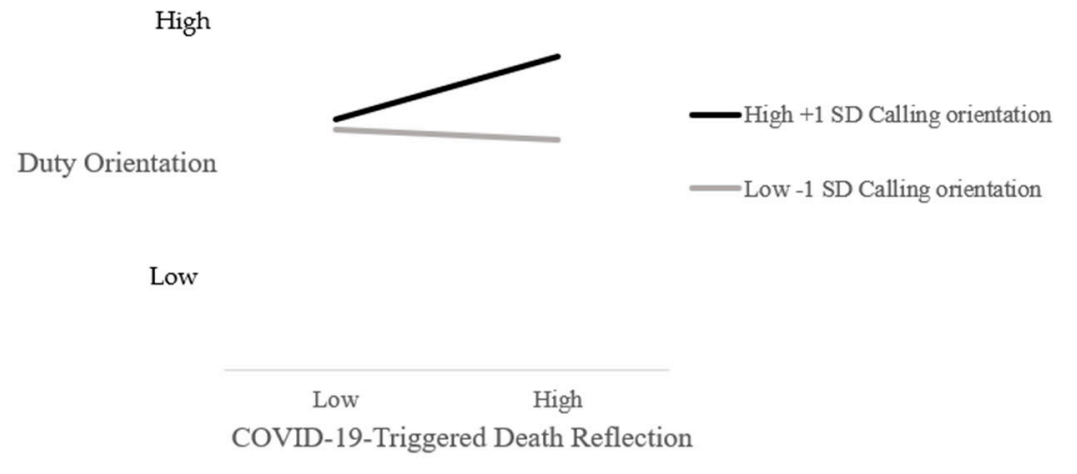

Figure 2. (a-c) The Effects of COVID-19-Triggered Death Reflection on Duty Orientation as a Function of Work Orientation.

For career orientation, the conditional indirect effect of COVID-triggered death reflection on IRP via duty orientation was significant when career orientation was high (+ $1 S D$, indirect effect $=0.12,95 \% \mathrm{CI}=[0.065,0.441]$ ) compared with when career orientation was low $(-1 S D$, indirect effect $=0.03,95 \% C I=[-0.190,0.103])$ (see Table 4$)$. The conditional indirect effect of COVID-triggered death reflection on OCBI via duty orientation was significant when career orientation was high $(+1 S D$, indirect effect $=0.14,95 \% C I=[0.051$, $0.365]$ ) compared with when career orientation was low $(-1 S D$, indirect effect $=0.06$, $95 \% \mathrm{CI}=[-0.072,0.026])$ (see Table 4$)$. The conditional indirect effect of COVID-triggered 
death reflection on OCBO via duty orientation was significant when career orientation was high $(+1 S D$, indirect effect $=0.13,95 \% \mathrm{CI}=[0.082,0.583])$ compared with when career orientation was low $(-1 S D$, indirect effect $=0.07,95 \% \mathrm{CI}=[-0.107,0.093])$ (see Table 4$)$.

Table 4. Estimates and Bias-Corrected Bootstrapped 95\% Confidence Intervals for the Conditional Effect of COVID-19-Triggerd Death Reflection on Job Performance (via Duty Orientation) at $\pm 1 S D$ of Career Orientation.

\begin{tabular}{cccc}
\hline Outcome Variable & Level of Job Orientation & Indirect Effect & Confidence Interval \\
\hline IRP & $-1 S D$ & 0.03 & {$[-0.190,0.103]$} \\
& $+1 S D$ & 0.12 & {$[0.065,0.441]$} \\
OCBI & $-1 S D$ & 0.06 & {$[-0.072,0.026]$} \\
\multirow{2}{*}{ OCBO } & $+1 S D$ & 0.14 & {$[0.051,0.365]$} \\
& $-1 S D$ & 0.07 & {$[-0.107,0.093]$} \\
& $+1 S D$ & 0.13 & {$[0.082,0.583]$}
\end{tabular}

Note: $\mathrm{N}=387$. IRP $=$ In-Role Performance. OCBI = Organizational Citizenship Behaviors toward Individuals $\mathrm{OCBO}=$ Organizational Citizenship Behaviors toward Organization. Bootstrap sample size $=5000$.

For calling orientation, the conditional indirect effect of COVID-triggered death reflection on IRP via duty orientation was significant when calling orientation was high $(+1 S D$, indirect effect $=0.07,95 \% \mathrm{CI}=[0.034,0.372])$ compared with when calling orientation was low $(-1 S D$, indirect effect $=0.02,95 \% \mathrm{CI}=[-0.079,0.042])$. The conditional indirect effect of COVID-triggered death reflection on OCBI via duty orientation was significant when calling orientation was high $(+1 S D$, indirect effect $=0.11,95 \% C I=[0.042$, $0.393])$ compared with when calling orientation was low $(-1 S D$, indirect effect $=0.02$, $95 \% \mathrm{CI}=[-0.048,0.017])$. The conditional indirect effect of COVID-triggered death reflection on OCBO via duty orientation was significant when calling orientation was high $(+1 S D$, indirect effect $=0.10,95 \% \mathrm{CI}=[0.072,0.0631])$ compared with when calling orientation was low $(-1 S D$, indirect effect $=0.03,95 \% \mathrm{CI}=[-0.112,0.087])$. Together, hypotheses $3 b, 4 b$, and $5 b$, thus, received support.

Furthermore, it is possible that there exists a three-way interaction such that both career orientation and calling orientation were interacted with COVID-19-triggered death reflection to have a positive effect on employees' in-role performance or OCBs engendered by duty orientation. Although not hypothesized, results of a post hoc analysis indicated that the three-way interaction was statistically significant $(b=0.13, p<0.05)$. This result was not very hard to understand because both career-oriented and calling-oriented employees consider work as a relative more important part of life compared with job-orientated employees and thereby they tend to express their generative motivation or behaviors within the domain of work when experiencing death reflection related to mortality. Please refer to Table 5 for more detail.

Table 5. Estimates and Bias-Corrected Bootstrapped 95\% Confidence Intervals for the Conditional Effect of COVID-19-Triggerd Death Reflection on Job Performance (via Duty Orientation) at $\pm 1 S D$ of Calling Orientation.

\begin{tabular}{cccc}
\hline Outcome Variable & Level of Job Orientation & Indirect Effect & Confidence Interval \\
\hline IRP & $-1 S D$ & 0.02 & {$[-0.079,0.042]$} \\
& $+1 S D$ & 0.07 & {$[0.034,0.372]$} \\
OCBI & $-1 S D$ & 0.02 & {$[-0.048,0.017]$} \\
\multirow{2}{*}{ OCBO } & $+1 S D$ & 0.11 & {$[0.042,0.393]$} \\
& $-1 S D$ & 0.03 & {$[-0.112,0.087]$} \\
& $+1 S D$ & 0.10 & {$[0.072,0.0631]$} \\
\hline
\end{tabular}

Note: $\mathrm{N}=387$. IRP $=$ In-Role Performance. $\mathrm{OCBI}=$ Organizational Citizenship Behaviors toward Individuals. OCBO = Organizational Citizenship Behaviors toward Organization. Bootstrap sample size $=5000$. 


\subsection{Discussion of Results}

The current research utilized generativity theory to develop and test a theoretical model about how and when death reflection enhanced duty orientation as well as employees' in-role and extra-role performance under the COVID-19 pandemic. Specifically, our findings show that high level of duty orientation can be increased by COVID-19-triggered death reflection, which allows employees to positively contribute to organizational development in the form of higher in-role performance, OCBI, and OCBO. Further, the mediated correlations of COVID-19-triggered death reflection with employees' work behaviors were also adjusted by three types of work orientation, such that the positive relationships were stronger for employees with high career orientation and high calling orientation, while the positive relationship was weaker when employees with high job orientation.

\subsubsection{Theoretical Implications}

Our research enriches the existing literature on organizational behaviors in the following ways. First, our research focused on the positive effects of death-related event. Past research largely focused on the negative effects of the COVID-19 pandemic or other mortality cues on employees such as anxiety, absenteeism, and withdrawal [1,4]. Moreover, our study fills the research gap about the death reflection and workplace outcomes. Past research mostly explored the effects of death reflection on family or personal life $[10,28]$. However, Brown and Lowis [40] claimed that human generativity include work, plans, and ideas that are related to the task of taking care of the next generation or looking forward to the future world. Therefore, it is necessary to study the impacts of death reflection in the workplace. The current study fills this research gap by showing death reflection can foster duty orientation and work behaviors of employees within the domain of work.

Second, our study reveals the partial mediating role of duty orientation on the relationship between death reflection and employees' in-role and extra-role performance. Drawing on the generativity theory [16], the research demonstrated that death reflection can be considered as a major antecedent to facilitate employees' duty orientation and subsequently their work behaviors including IRP and OCBs within the work domain. When employees experience death reflection, they develop strong desires to make self-transcendent contributions or feel connected with others and show the positive behaviors towards co-workers or groups.

Third, our study draws on resource allocation theories [23] to highlight employees' individual contingencies (work orientation) as the boundary condition that explains the situations where employees are more likely to respond to death-related events through increasing duty orientation and work behaviors in the workplace. To be specific, our findings indicate that employees with high career or calling orientation and that attach more meaning to work in their life domain, Wrzesniewski, McCauley [26], tend to show higher level of duty orientation when they reflect on death. This in turn was found to motivate them to show better in-role performance and engage in extra-role behaviors promoting both the organization and colleagues. The findings also suggest employees with high job orientation will express lower level of duty orientation and job performance when they experience death reflection related to the COVID-19 pandemic. This is primarily because employees with job orientation will not define personal identity by work alone, and thereby, they may express their prosocial generative motivations induced by death reflection outside the work domain and invest less time and energy to work. Together, our study suggests that the influence of death reflection on employees' job performance (IRP, OCBI, and OCBO) through duty orientation's mediating mechanism depends on employee's work orientation types.

Finally, given that duty orientation remains to be a relatively new theoretical concept, there is a gap in people's understanding of its antecedents and outcomes. This research, based on a recent study [29], examines death reflection as a new antecedent for duty orientation under the COVID-19 pandemic, which serves as a mediating mechanism to connect COVID-19-triggered death reflection with employees' positive work behaviors. 


\subsubsection{Practical Implications}

For individuals, the results imply that cool psychological processes deserve more attention in the post-pandemic era. It potentially helps individuals return to the rational track by realizing the effectiveness of death reflection and its differences from death anxiety. Since we have entered the stage of prevention and control for the COVID-19 pandemic, it is especially important to note that, though the surroundings are still awash with mortality cues, individuals need to buffer against the state of anxiety and adapt to environmental uncertainty and disruption and make efforts to turn to meaningful activities.

For managers, employee management can make profit from our findings on cognitive state of death awareness. Death is widely perceived as a sensitive and loaded topic, organizations generally provide few guidelines to deal with death. Besides, managers are often overwhelmed by uncertainty and confused about how to cope with increasing mortality events in the workplace. Our study may assist managers in understanding and managing death-related events. The results of current research suggest that when mortality cues emerge, managers generate benefits from supporting reflection rather than covering up the facts and sweeping the event under the rug, which is very important as a huge number of companies suffered the loss during the COVID-19 pandemic. Managers should acknowledge that death awareness can be symbolized by rational contemplation instead of crippling anxiety. Moreover, its generativity effects deserve much attention considering the necessity to manage the pandemic over the long term. We suggest that organizational efforts should be made to promote employees' psychological transition towards death reflection, and the first step to survey the emotional states of employees during the COVID19 pandemic. Furthermore, organizations can conduct seminars or lectures to strengthen employees' awareness of death reflection and give correct guidance on their confusion.

Considering the role of individual contingencies, managers should also be concerned with the work orientation of employees in the COVID-19 pandemic context. Due to the significant but different values endowed by career-oriented, calling-oriented, and joborientated employees with their work, they may have different principles of resource allocation, therefore, it is imperative for managers to distinguish and realize why employees engage in work and have different generative responses to death-related events. Accordingly, some managerial attempts can be taken into practice by cultural construction predominant of work significance in life. Specifically, organizations can invest in the career development of employees, to associate the work strongly with employees' identities. Besides, if managers try to encourage employees with high calling orientation to do more generative behaviors in workplace during the COVID-19 pandemic, it will be particularly crucial to utilize job design or job rotation because when calling-oriented employees recognize helping or mentoring opportunities, they may craft their jobs and provide more help and mentoring and tend to show high levels of effort and persistence [1]. Moreover, if managers plan to facilitate generative behavior among job-oriented employees, it may be important to offer financial rewards This may motivate employees with high job orientation to invest more time in generative behaviors.

\section{Conclusions, Limitations and Future Research}

The present study examined the effects of COVID-19-triggered death reflection on both employee's in-role performance and organizational citizenship behaviors as well as mediating mechanisms of duty orientation on such relationships. Additionally, it examined whether the mediated effects are contingent on the work orientation rooted in employees. Using multi-source and time-lagged data from Chinese public and private sectors, duty orientation was found to play a mediating role in the relationship between death reflection and work outcomes named in-role performance, OCBI and OCBO. Furthermore, the relationships between death reflection and work outcomes were found to be stronger among employees with high career orientation and high calling orientation and low job orientation. Our findings suggest that death reflection related to the COVID-19 pandemic can facilitate employees' work behaviors, and when death-related events emerge, it is 
important for organizations to provide adequate instructions for employees instead of avoiding them.

As with any research, the current research still has some limitations. First of all, the current study has some methodological limitations. Since we failed to collect all variables data at all points in time, it is unable for us to conclusively determine causal relationships among the observed variables. For strengthening the causal relationships, researchers should examine variables by using the cross-lagged panel or experimental designs. Further, self-report data concerns with common method bias, which has been weakened in the study, to some extent, through time-lagged design of three surveys with approximately one-week interval [41]. The statistical test finally supported that a common method factor involved made no significant improvement on our model. However, as Cooper, Eva [42] suggested, there are also concerns with endogeneity due to reverse causation, and it is preferable to make procedural remedies by data from multiple sources or undertake more experimental works.

Second, the generalizability of our research findings among different cultures and organizations may be brought into question because we used a sample from a single province of China. To overcome this limitation, researchers are advised to replicate the current research in various cultural contexts or organizational settings.

Finally, although the current research has started to uncover the underlying boundary conditions for death reflection's effects on employee work outcomes via duty orientation through examining different types of work orientation, researchers are advised to explore other possible moderators in the future. Specifically, empirical research can test if contextual contingencies like job design, organizational climate, or leadership may reinforce death reflection's effects on duty orientation and positive work behaviors.

Author Contributions: All of the authors contributed to conceptualization, formal analysis, investigation, methodology, and writing and editing of the original draft. All authors have read and agreed to the published version of the manuscript.

Funding: This research received no external funding.

Institutional Review Board Statement: Not applicable.

Informed Consent Statement: Not applicable.

Data Availability Statement: The data will be made available on request from the corresponding author.

Conflicts of Interest: The authors declare no conflict of interest.

\section{References}

1. Grant, A.M.; Wade-Benzoni, K.A. The hot and cool of death awareness at work: Mortality cues, aging, and self-protective and prosocial motivations. Acad. Manag. Rev. 2009, 34, 600-622.

2. Larrick, R.P. Motivational factors in decision theories: The role of self-protection. Psychol. Bull. 1993, 113, 440. [CrossRef]

3. Belmi, P.; Pfeffer, J. Power and death: Mortality salience increases power seeking while feeling powerful reduces death anxiety. $J$. Appl. Psychol. 2016, 101, 702. [CrossRef]

4. Hu, J.; He, W.; Zhou, K. The mind, the heart, and the leader in times of crisis: How and when COVID-19-triggered mortality salience relates to state anxiety, job engagement, and prosocial behavior. J. Appl. Psychol. 2020, 105, 1218-1233. [CrossRef]

5. Takeuchi, R.; Guo, N.; Teschner, R.S.; Kautz, J. Reflecting on death amidst COVID-19 and individual creativity: Cross-lagged panel data analysis using four-wave longitudinal data. J. Appl. Psychol. 2021, 106, 1156. [CrossRef]

6. Metcalfe, J.; Mischel, W. A hot/cool-system analysis of delay of gratification: Dynamics of willpower. Psychol. Rev. 1999, 106, 3-19. [CrossRef] [PubMed]

7. Becker, G.S. A theory of the allocation of time. Econ. J. 1965, 75, 493-517. [CrossRef]

8. Haidt, J. The emotional dog and its rational tail: A social intuitionist approach to moral judgment. Psychol. Rev. 2001, 108, 814. [CrossRef]

9. Zhong, R.; Paluch, R.M.; Shum, V.; Zatzick, C.D.; Robinson, S.L. Hot, cold, or both? A person-centered perspective on death awareness during the COVID-19 pandemic. J. Appl. Psychol. 2021, 106, 839. [CrossRef]

10. Frias, A.; Watkins, P.C.; Webber, A.C.; Froh, J.J. Death and gratitude: Death reflection enhances gratitude. J. Posit. Psychol. 2011, 6, 154-162. [CrossRef]

11. Vail, K.E., III; Juhl, J.; Arndt, J.; Vess, M.; Routledge, C.; Rutjens, B.T. When death is good for life: Considering the positive trajectories of terror management. Personal. Soc. Psychol. Rev. 2012, 16, 303-329. [CrossRef] 
12. Zacher, H.; Rosing, K.; Frese, M. Age and leadership: The moderating role of legacy beliefs. Leadersh. Q. 2011, 22, 43-50. [CrossRef]

13. Grant, A.M. Giving time, time after time: Work design and sustained employee participation in corporate volunteering. Acad. Manag. Rev. 2012, 37, 589-615. [CrossRef]

14. Lee, T.W.; Hom, P.W.; Eberly, M.B.; Mitchell, T.R.; Li, J. On the next decade of research in voluntary employee turnover. Acad. Manag. Perspect. 2017, 31, 201-221. [CrossRef]

15. Yuan, Z.; Baranik, L.E.; Sinclair, R.R.; Sliter, M.T.; Rand, K.L.; Salyers, M.P. Memento Mori: The development and validation of the Death Reflection Scale. J. Organ. Behav. 2019, 40, 417-433. [CrossRef]

16. McAdams, D.P.; de St Aubin, E. Generativity and Adult Development; American Psychological Association: Washington, DC, USA, 1998.

17. Routledge, C.; Ostafin, B.; Juhl, J.; Sedikides, C.; Cathey, C.; Liao, J. Adjusting to death: The effects of mortality salience and self-esteem on psychological well-being, growth motivation, and maladaptive behavior. J. Personal. Soc. Psychol. $2010,99,897$. [CrossRef]

18. Moss, S.E.; Song, M.; Hannah, S.T.; Wang, Z.; Sumanth, J.J. The duty to improve oneself: How duty orientation mediates the relationship between ethical leadership and followers' feedback-seeking and feedback-avoiding behavior. J. Bus. Ethics 2020, 165, 615-631. [CrossRef]

19. Eva, N.; Newman, A.; Miao, Q.; Wang, D.; Cooper, B. Antecedents of duty orientation and follower work behavior: The interactive effects of perceived organizational support and ethical leadership. J. Bus. Ethics 2020, 161, 627-639. [CrossRef]

20. Williams, L.J.; Anderson, S.E. Job satisfaction and organizational commitment as predictors of organizational citizenship and in-role behaviors. J. Manag. 1991, 17, 601-617. [CrossRef]

21. Lee, K.; Allen, N.J. Organizational citizenship behavior and workplace deviance: The role of affect and cognitions. J. Appl. Psychol. 2002, 87, 131-142. [CrossRef]

22. James, J.B.; Zarrett, N. Ego integrity in the lives of older women. J. Adult Dev. 2006, 13, 61-75. [CrossRef]

23. Hobfoll, S.E. Social and psychological resources and adaptation. Rev. Gen. Psychol. 2002, 6, 307-324. [CrossRef]

24. Wrzesniewski, A.; Dutton, J.E.; Debebe, G. Interpersonal sensemaking and the meaning of work. Res. Organ. Behav. 2003, 25, 93-135. [CrossRef]

25. McKevitt, D.; Carbery, R.; Lyons, A. A profession but not a career? Work identity and career satisfaction in project management. Int. J. Proj. Manag. 2017, 35, 1673-1682.

26. Wrzesniewski, A.; McCauley, C.; Rozin, P.; Schwartz, B. Jobs, careers, and callings: People's relations to their work. J. Res. Personal. 1997, 31, 21-33. [CrossRef]

27. Lykins, E.L.; Segerstrom, S.C.; Averill, A.J.; Evans, D.R.; Kemeny, M.E. Goal shifts following reminders of mortality: Reconciling posttraumatic growth and terror management theory. Personal. Soc. Psychol. Bull. 2007, 33, 1088-1099. [CrossRef]

28. Cozzolino, P.J.; Staples, A.D.; Meyers, L.S.; Samboceti, J. Greed, death, and values: From terror management to transcendence management theory. Personal. Soc. Psychol. Bull. 2004, 30, 278-292. [CrossRef]

29. Hannah, S.T.; Jennings, P.L.; Bluhm, D.; Peng, A.C.; Schaubroeck, J.M. Duty orientation: Theoretical development and preliminary construct testing. Organ. Behav. Hum. Decis. Process. 2014, 123, 220-238. [CrossRef]

30. Wade-Benzoni, K.A. Legacies, immortality, and the future: The psychology of intergenerational altruism. In Ethics in Groups; Emerald Group Publishing Limited: Bingley, UK, 2006.

31. Peterson, B.E.; Stewart, A.J. Antecedents and contexts of generativity motivation at midlife. Psychol. Aging 1996, 11, 21. [CrossRef]

32. Bellah, R.N.; Madsen, R.; Sullivan, W.; Swidler, A.; Tipton, S.M. Habits of the Heart: Commitment and Individualism in American Life; Harper and Row: New York, NY, USA, 1985.

33. Lan, G.; Okechuku, C.; Zhang, H.; Cao, J. Impact of job satisfaction and personal values on the work orientation of Chinese accounting practitioners. J. Bus. Ethics 2013, 112, 627-640. [CrossRef]

34. Shea-Van Fossen, R.J.; Vredenburgh, D.J. Exploring differences in work's meaning: An investigation of individual attributes associated with work orientations. J. Behav. Appl. Manag. 2014, 15, 101-120. [CrossRef]

35. Gazica, M.W.; Spector, P.E. A comparison of individuals with unanswered callings to those with no calling at all. J. Vocat. Behav. 2015, 91, 1-10. [CrossRef]

36. Chen, J.; May, D.R.; Schwoerer, C.E.; Augelli, B. Exploring the boundaries of career calling: The moderating roles of procedural justice and psychological safety. J. Career Dev. 2018, 45, 103-116. [CrossRef]

37. Bernerth, J.B.; Aguinis, H. A critical review and best-practice recommendations for control variable usage. Pers. Psychol. 2016, 69, 229-283. [CrossRef]

38. Ng, T.W.; Feldman, D.C. Affective organizational commitment and citizenship behavior: Linear and non-linear moderating effects of organizational tenure. J. Vocat. Behav. 2011, 79, 528-537. [CrossRef]

39. Hackman, J.R.; Hackman, R.J.; Oldham, G.R. Work Redesign; Addison-Wesley: Reading, MA, USA, 1980; Volume 2779.

40. Brown, C.; Lowis, M.J. Psychosocial development in the elderly: An investigation into Erikson's ninth stage. J. Aging Stud. 2003, 17, 415-426. [CrossRef]

41. Podsakoff, P.M.; MacKenzie, S.B.; Podsakoff, N.P. Sources of method bias in social science research and recommendations on how to control it. Annu. Rev. Psychol. 2012, 63, 539-569. [CrossRef]

42. Cooper, B.; Eva, N.; Fezlelahi, F.Z.; Newman, A.; Lee, A.; Obschonka, M. Common method variance in vocational behavior research: Reviewing the state of the literature. J. Vocat. Behav. 2020, 121, 103472. [CrossRef] 